\title{
Study of the Sports Precision Marketing Model under Big Data Environment
}

\author{
Xiaoyan Zhou ${ }^{1, *}$ and Fei Huang ${ }^{2}$ \\ ${ }^{1}$ School of Sports Science and Engineering, East China University of Science and Technology, Shanghai 200237, China \\ ${ }^{2}$ Department of Human Resources, East China University of Science and Technology, Shanghai 200237, China \\ *Corresponding author
}

\begin{abstract}
Under the influence of big data environment, the sports marketing method becomes more personalized and precise. Sports precision marketing is based on the characteristics of consumer behavior of sports target market. It is the combination of quantitative and qualitative analysis methods for targeted marketing. By applied literature and example analysis, this paper pointed out the influence of large data environment on sports marketing. It made systematic study on the basic flow of precise sports marketing, and constructed a novel sports precision marketing model. The model provides a theoretical and practical reference for the research and application of big data technology and the innovation of marketing model in the field of sports.
\end{abstract}

Keywords—big data; sports; precision marketing; model

\section{INTRODUCTION}

With the rapid development of the Internet, the Internet of Things, and cloud computing, the era of big data has arrived. The traditional sports marketing model can no longer meet the needs. Hence, how to realize the sports marketing model innovation in the big data environment has become a popular topic of the industry. By use of the big data technology, the transformation and development of sports enterprise marketing activities are promoted. Also, it can integrate and analyze massive data of sports, quickly and accurately mine the regularity, orderliness and relevance of sports data, obtain ideal information, and provide personalized sports products or services for consumers. By which, the precision and personalization of sports marketing can be achieved [1,2].

\section{THE Literature REVIEW ON THE PRECISION MARKETING MODEL OF SPORTS}

\section{A. The Meaning of Sports Precision Marketing}

Lester had proposed precision marketing theory in 1999 [3]. Different from traditional marketing channels and methods, this theory focuses on producers and distributors, builds customer database through network, telephone, and communication, etc. Furthermore, marketer can finds out potential customers, and formulates corresponding promotion strategies and marketing plans. Based on the potential consumers and their consumption behaviors, the target market is segmented and positioned. Finally, the expected marketing objectives can be achieved.

As a new modern marketing method, the basis of precision marketing is the analysis of consumers. The method generally includes customer information collection and processing, market segmentation and positioning, marketing strategy formulation, marketing plan design and result feedback stages [4].

In the marketing activities of sports enterprises, the collection, storage, processing, analysis and application of data play a decisive role in marketing decision-making. In the era of big data, the pattern of sports consumption behavior has taken place fundamental changes, and the precise marketing model will become an important choice for the sports industries.

\section{B. Related Researches}

In recent years, with the rapid development of big data technology, some scholars and researchers have begun to introduce the big data technology and precision marketing concepts to the sports industry and research in the sports field.

Jingliang Xie (2015), Yuqun Zhang (2016) and Guoquan Ma (2015) et al. studied systematically the applications of big data in national health, sports media, sports performance improvement and anti-doping conduct fields $[1,5,6]$. Jun Zhou (2015) applied big data technology to the data analysis of online sports news [7]. Qingqun Xiao (2016) proposed the development strategy of national characteristics sports in Guizhou based on big data technology [8]. In sports precision marketing, Shenglu Huo (2012) used precision marketing theory to the sports games in China, and pointed out the main problems existing [9]. Yue $\mathrm{Hu}$ (2016) proposed to use precision methods to the spread of advertising in commercial football events [10].

From the relevant literatures, because of factors from the technical level, the research is not systematic and deep in the aspects of sports big data collecting, storage and processing. Due to the privacy protection for the sports consumers, there is less open sharing of data, which makes it impossible to achieve fine marketing. Meanwhile, a large number of idle sports data cannot be used reasonably and effectively. The literature that combines big data technology and sports to achieve precision marketing is less. The collaborative innovation mechanism, research and application of sports big data also needs to be expanded.

\section{The IMPACT OF BIG DATA TECHNOLOGY ON SPORTS MARKETING}

The big data technology has had a profound impact on the sports industry. The sports big data marketing is based on technology-driven, personalized and precise marketing for specific consumers, and whose core is the massive data mining. 


\section{A. Sports Marketing Modes is Becoming More Electronic and} Digitalization

In the era of big data, with the increasing popularity of the Internet and mobile platforms, sports marketing entities are expanding and marketing content is more abundant. The marketing types includes: (1) Sports games marketing (Sports competitions, sponsorship and naming rights of competitive performances, tickets, television broadcasts and media campaigns, derivatives and franchises; Sports tourism and sports-themed travel marketing of sports games and sports exhibitions). (2) Stadium marketing (Sports information, venue reservations of the fitness and entertainment venues, clubs; Sports marketing of the communities and virtual communities). (3) Sports media marketing (Sports dissemination, live events interaction, sports social and sports forums, etc.) (4) Sports goods marketing (All kinds of sporting goods, material, equipment, clothing, shoes, hats and other supplies retail). (5) Sports service marketing (Sports intermediary, technical training and consulting, sports lottery, betting, and games, etc.)

Furthermore, it has triggered a fundamental change in the sports marketing from product-driven to consumer-driven, and marketing methods have become more and more electronic and digitizing. The sale of sports products or services through portals, e-mail, QQ, Weibo, forums, WeChat, Facebook and social media has become the main marketing mode.

The information such as the search behavior and transaction process of sports consumers are collected and completely recorded, forming a massive data resource of the sports marketing system. Data analysis will play a central role in sports enterprise marketing decision-making. The organizational structure, staff composition and work content of sports enterprises will be carried out around the collection, analysis and processing of sports data [2]. Competitive behaviors aimed at sports data competition, information collection and technical competition will become more intense in the sports industry.

\section{B. Sports Marketing Behavior is Becoming More Personalized and Precise}

At present, the interactive, precise marketing around big data has become the focus. In the sports precision marketing activities, consumers are no longer pure consumers, but active participants and active value creators [11]. According to the consumption habits and propensities of consumers, sports enterprises accurately carry out the market positioning and customer segmentation. Then, targeted sports marketing strategies, quantitative $\mathrm{R} \& \mathrm{D}$, fine production, targeted push, personalized recommendation are formed, and a better competitive advantage in the sports market is obtained.

For sports consumers, it can quickly filter and order suitable sports goods or services. Also, it can choose personalized sports goods or services. By which, the buyers can enhance the experience and greatly save the cost. For sports service providers, through online and offline data tracking, they can conduct data analysis and data mining, accurate posit the sports consumer groups. Thus, it results in a large number of high-viscosity sports consumer groups, master huge sports consumer data resource. Through in-depth analysis, clues to discover new customers can be provided, traffic can be predicted and even be controlled. Based on the analysis the consumers' preferences, sports goods or services by online and offline can be reasonably arranged, consumers can be provided with more abundant, comprehensive, more competitive and efficient sports goods or services, and value-added and sharing of sports data can be realized.

\section{Sports Marketing Decisions are Being Socialized and Intelligent}

Today, many sports companies have begun to value and utilize the collected sports data resources. They integrate sports product value chains, conduct quantitative research and development, fine production, and precise marketing. It will lead to the less dependence on storefronts and geographical locations, lower marketing costs, and improved marketing effectiveness.

Sports consumers' information greatly affects the supply and sales of sports enterprises' production and services. Many sports companies absorb ordinary consumers to directly participate in the research and development and sales of sports products and services. Thus, it will promote the socialization and intelligence of sports production and sales, sharing of resources, tools and information [11]. The intelligentization is mainly reflected in the production process and sales of sports enterprises. It provides the possibility of customized production and precise marketing of sporting goods and services, and improves the success rate of research and development of new sports products.

\section{CONSTRUCTION OF SPORTS PRECISION MARKETING MODEL IN BIG DATA ENVIRONMENT}

Sports precision marketing in the big data environment is necessary to establish processing procedures and modes that suitable for the characteristics of the sports industry. The core of the sports precision marketing model is "customer-centric". Its connotation includes marketing opportunities, business, channels, actions, etc. According to different needs, combined with sports consumption behavior, customer relationship and customer database, marketers collect, storage, analyze and mine of sports consumer market and sports consumer behavior characteristics. Then, they interpret and express these data, and accurately identify the sports market, design targeted marketing decisions and marketing strategies. Finally, a sports precision marketing model is formed [12, 13]. Based on this model, a corresponding sports precision marketing scenario can be constructed. In the implementation, it is necessary to evaluate the marketing results so as to continuously improve the sports precision marketing model. Using the above process, this paper constructs a sports precision marketing model in the big data environment, as shown in Figure I. 


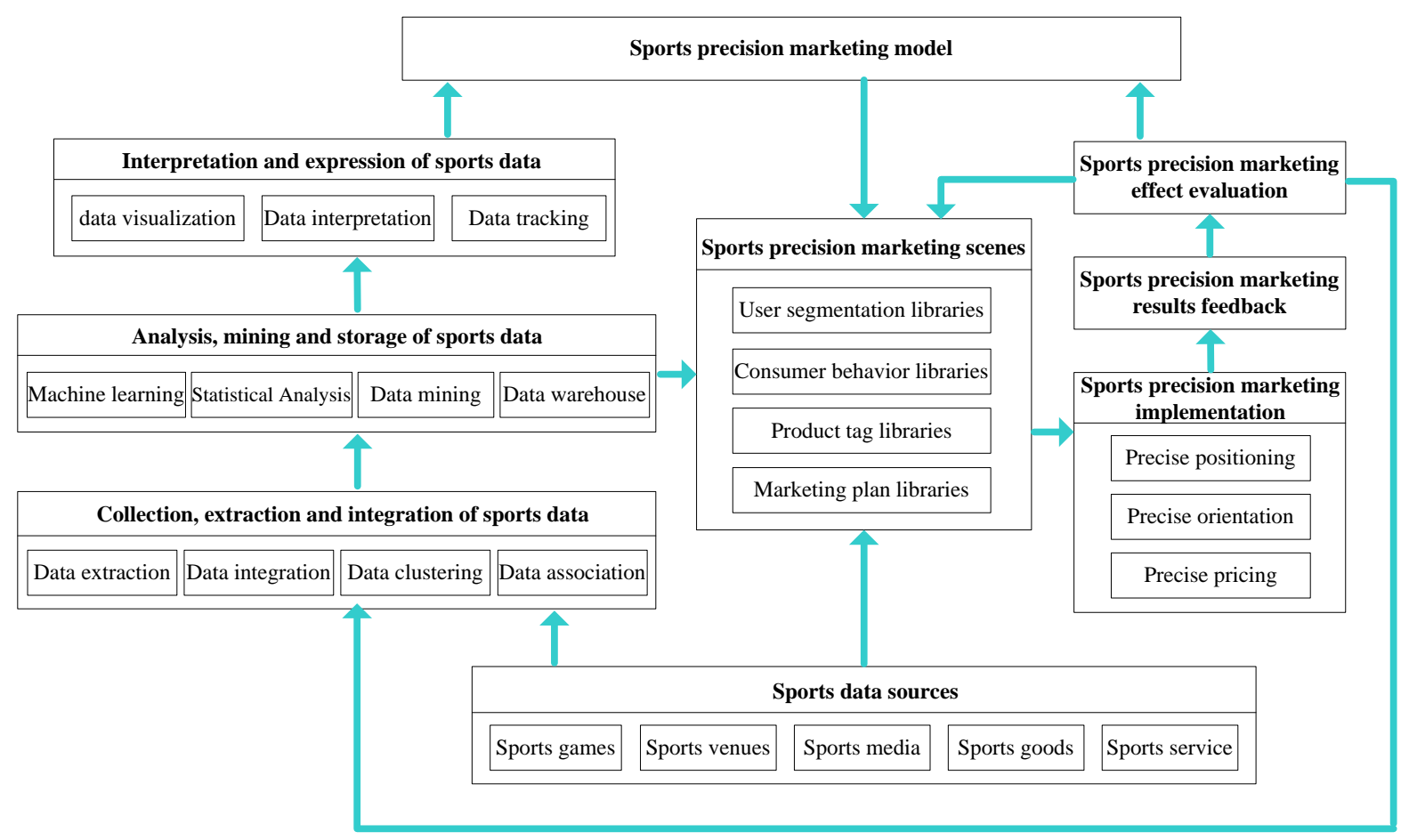

FIGURE I. SPORTS PRECISION MARKETING MODEL UNDER BIG DATA ENVIRONMEN

\section{A. Collection, Extraction and Integration of Sports Data}

Before developing a sports marketing plan, it is first necessary to collect data that reflects the sports consumer market and consumer behavior. These data come from five major data sources: sports games, sports venues, sports media, sporting goods and services. The data is extracted and integrated, and the relationships and entities are built. After aggregation and association, they are stored with a unified structure. In the end, an initial sports database is formed. In this process, the data needs to be cleaned to ensure the reliability and quality.

\section{B. Analysis, Mining and Storage of Sports Data}

The sports industry generates large amounts of structured, semi-structured or unstructured data every day. Using machine learning, statistical analysis, data mining, data warehousing, cloud computing and other technical methods, we can find information that is benefit for the analysis and prediction of the sports market. Due to the noise of the sports data, pre-processing such as data cleaning must be performed. Second, because of the real-time requirements of many applications, improvements to conventional analysis and mining algorithms are needed.

After statistical analysis and mining, real-time database, cloud storage and other data storage technologies are used to store data. An intermediate database is established that includes sports consumers' data and sports products' data. Former includes basic registration information of consumer, user relationship network, user behavior information, and recent consumption information. The latter contains sports product positioning, target customers, product evaluation, and the recommended information of the sports product, etc. [14]

\section{Interpretation, Expression and Tracking of Sports Data}

This section interprets the results of statistical analysis and data mining, which use visualization technology such as graphics rendering, image processing, computer vision and user interface. It is sometimes necessary to track sports data with the techniques such as human-computer interaction, and to trace the statistical analysis process of sports marketing data $[15,16]$.

Sports big data reveals the possible correlation between variables from a certain perspective [6]. It requires the executives of the interpretation, expression and tracking of sports big data, a certain knowledge of the sports field, and familiar with the main focus of sports marketing.

\section{Construction of Sports Precision Marketing Model and Marketing Scene}

Under the guidance of precision marketing theory, through the precise segmentation of sports products or service market, we can accurately select and locate the target market, and construct the sports precision marketing model.

The model is used to guide the establishment of sports precision marketing scenarios. The potential customers are mined, and the segmented market is established. These provide a reliable basis for locating the sports target market. It is also necessary to draw different sports data sources. Using above information, the classification library of sports customers, the consumption behaviors library, product tag library, and marketing plan library are established. Using the customer knowledge and information resource library, marketers predict the corresponding consumer groups and the future consumption behavior, and determine the marketing strategy. 
E. Implementation of Sports Precision Marketing and Evaluation of Marketing Effect

In implementation, using personalized recommended technology, accurate information is transferred and personalized marketing of sports products is customized. It is possible to help customers quickly find enjoyed product. Some related sports items is recommended based on the items in the current shopping cart. The purchasing preferences of the customers is analyzed, key customers are filtered out, and some new products that may cause sports customers' interest are regularly recommended [17]. The key is to accurately target the sports market through resource indexing, accurate search, precise targeting of sports customers, reasonably determine the price of goods, and design appropriate marketing methods and measures.

Another important step is the evaluation of sports precision marketing effectiveness. The evaluation results will be used to improve the marketing model and marketing scene.

\section{CONCLUSION AND SUGGESTION}

At present, the sports marketing model is developing in the direction of precision and personalized. Big data provides massive data support for sports precision marketing. In the result, sports consumers can be provided with more personalized products and services. However, there are still many problems in the sports precision marketing, and some challenges are still be faced. It is necessary to actively explore measures to promote sports precision marketing under the big data environment.

\section{A. Change Consciousness, Pay Attention to the Development and Utilization of Sports Marketing Data}

Sports management personnel must adapt to three core shifts. They are: (1) the transform from relying on random sampling to processing all sports data; (2) the transform from the pursuit of the accuracy of individual sports data to the general direction of the comprehensive data; (3) the transform from the enthusiasm of seeking causality to the identification the relationship between of the sports items and sports phenomena $[18,19]$.

\section{B. Convergence and Development, Achieve the Collaborative Innovation of Sports Marketing Big Data}

Government departments should encourage sports enterprises to carry out multi-faceted collaborative innovation in the use of sports marketing big data, establish a sports marketing big data development strategy, formulate corresponding laws and regulations, and give appropriate inclinations in policies. Sports enterprises should actively cooperate with colleges, research institutions, industry associations, government and other departments to share sports big data [1].

\section{Innovate Sports Product and Service Research and Development, and Improve Marketing Targeting}

Utilize sports big data, the marketers integrate sports industry chain, collect and analyze consumption information, combine sports enterprise strategy, ability, market environment and other factors to find possible business opportunities, predict consumption demand, innovate research and development of the products and services. According to the marketing goal, the markets design targeted sports marketing ideas, carefully conceive push content, and improve the accuracy of pricing.

\section{Open and Distribute Sports Data, and Cultivate Sports Professional Marketing Talents}

Drawing on the practices of the US government and large institutions such as IBM, it is recommended to make trade-offs between sports data privacy protection and the use of sports data privacy. Under the premise of not violating national laws, the relevant regulatory agencies should be established to open and share various sports data. And, it should actively cultivate sports professional marketing talents who master big data technology.

\section{ACKNOWLEDGMENT}

This research was financially supported by the Shanghai Sports Social Science Decision-making Consulting Project. (Grant No. TYSKYJ2016048).

\section{REFERENCES}

[1] J. L. Xie, J. H. Sun, and L. Cao, "Opportunities and Challenges for the Development of Sports Industry during the Age of Big Data,"Journal of Shanghai University of Sport, vol. 39, pp. 59-63, July 2015.

[2] H. C. Luo, "Research on the Marketing Model of Sports Products in China from the Perspective of Big Data," Dissertation of Qufu Normal University, April 2016.

[3] Q. S. Wu, Y. Yu, and X. S. Zheng, "Thoughts and methods of precision marketing," Marketing Herald, pp. 39-42, Oct. 2006.

[4] B. Wang, and Z. Y. Wu, "Research on Precision Marketing Model in Big Data Era," Economist, pp. 14-16, May 2013

[5] Z. Q. Zhang, "Analysis and application of big data in sports field," Contemporary Sports Technology, vol. 6, pp. 150-151, April 2016.

[6] G. Q. Ma, J. W. Yang, H. X. Zhang, and Y. Tian, "Applications and Thoughts of Big Data in Sport Science," Journal of Hebei Institute of Physical Education, vol. 29, pp. 11-15, Mar. 2015.

[7] J. Zhou, "Analysis of network sports news data in big data Era," Dissertation of Xi'an Institute of Physical Education, April 2015.

[8] Q. Q. Xiao, and D. Y. Yang, "Sports Big Data and the Development Strategy for the Sports with the Characteristics of Guizhou Mountain," Journal of Guizhou Education University, vol. 32, pp. 13-17, April 2016.

[9] S. L. Huo, X. F. Lou, and C. Zhu, "Marketing strategy of events in China based on precision marketing," Journal of Shandong Institute of Physical Education and Sports, vol.28, pp. 13-18, Aug. 2012.

[10] Y. Hu, "Research On The Precision Of Advertising Communication In Commercial Football Matches," Journal of Jilin Sport University, vol. 32, pp. 49-52, Oct. 2016

[11] Y. Q. Xia, "Integration and Innovation: the Ecology of the Sports Industrial background the 'Internet +',' Journal of Nanjing Sport Institute, vol. 30, pp. 68-72, Jun. 2016

[12] Y. M. Gong, and X. B. Cao, "Research on Precision Marketing Pattern of Agricultural Products in Yunnan Province in the Big Data Environment," Journal of Kunming University of Science and Technology, vol. 16, pp. 65-71, Feb. 2016.

[13] F. Wang, "Based on Big Data Platform of Agricultural Products in Yunnan Province and Application Research on Precise Marketing Model," Jiangsu Business Theory, pp. 20-22, Nov. 2016.

[14] B. Y. Li, Z. S. Huang, and Z. L. Ye, "Research on the Characteristics and Precision Marketing mode of EC Based on Social Network," Logistics Engineering and Management, vol. 37, pp. 160-162, July 2015.

[15] X. F. Meng, and X. Ci, "Big Data Management: Concepts, Techniques and Challenges," Journal of Computer Research and Development, vol. 50, pp. 146-169, Jan. 2013. 
[16] H. Lei, T. Y. Lao, Z. Liu, W. H. Zuo, and W. Chen, "A Survey on Sports Data Visualization," Journal of Computer-Aided Design \& Computer Graphics, Vol. 27, pp. 1605-1616, Sep. 2015.

[17] X. M. Wei, J. Zhang, and X. S. Xiang, "Big Data Precision Marketing," Enterprise Management, pp. 91-93, April 2016

[18] H. Y. Yu, and Y. L. Huang, "What will sports be in the era of Big Data?" Journal of Shandong Sports University, vol. 31, pp.5-9, April 2015.

[19] X. S. He, and G. Wang, "The Change of Sports Science Research in the Age of Big Data," Sports Culture Guide, pp.29-32, Sep. 2014. 